Perspectives

\title{
Nanomaterials and water purification: Opportunities and challenges
}

\author{
Nora Savage ${ }^{1}$ and Mamadou S. Diallo,3 \\ ${ }^{1}$ National Center for Environmental Research, Office of Research and Development, US Environmental \\ Protection Agency, Washington, DC 20460, USA; ${ }^{2}$ Materials and Process Simulation Center, Beckman \\ Institute 139-74 California Institute of Technology, Pasadena, CA 91125, USA; ${ }^{3}$ Department of Civil \\ Engineering, Howard University, Washington, DC 20059, USA (Tel.: + 1-202-343-9858; E-mail: \\ savage.nora@epamail.epa.gov/Tel.:+1-626-395-8133; E-mail: diallo@wag.caltech.edu)
}

Received 9 March 2005; accepted in revised form 17 May 2005

Key words: nanomaterials, water quality, water purification, desalination, nanosorbents, nanocatalysts, nanofiltration, carbon nanotubes, dendrimers, membranes, nanoparticles, nanotechnology, water and wastewater

\begin{abstract}
Advances in nanoscale science and engineering suggest that many of the current problems involving water quality could be resolved or greatly ameliorated using nanosorbents, nanocatalysts, bioactive nanoparticles, nanostructured catalytic membranes and nanoparticle enhanced filtration among other products and processes resulting from the development of nanotechnology. Innovations in the development of novel technologies to desalinate water are among the most exciting and promising. Additionally, nanotechnology-derived products that reduce the concentrations of toxic compounds to sub-ppb levels can assist in the attainment of water quality standards and health advisories. This article gives an overview of the use of nanomaterials in water purification. We highlight recent advances on the development of novel nanoscale materials and processes for treatment of surface water, groundwater and industrial wastewater contaminated by toxic metal ions, radionuclides, organic and inorganic solutes, bacteria and viruses. In addition, we discuss some challenges associated with the development of cost effective and environmentally acceptable functional nanomaterials for water purification.
\end{abstract}

\section{Introduction}

Clean water (i.e., water that is free of toxic chemicals and pathogens) is essential to human health. Clean water is also a critical feedstock in a variety of key industries including electronics, pharmaceuticals and food. The world is facing formidable challenges in meeting rising demands of clean water as the available supplies of freshwater are decreasing due to (i) extended droughts, (ii) population growth, (iii) more stringent healthbased regulations, and (iv) competing demands from a variety of users (US Bureau of Reclamation,
2003). Increasingly, water scientists and engineers are questioning the viability of the current practice of meeting the water demands of all users according to increasingly stringent standards (Weber, 2002). Weber (2002) has proposed the distributed optimal technology networks (DOTNET) as an alternative to the 'huge centralized' water treatment plant. The DOT-NET concept is predicated upon the 'distribution and strategic placement of relatively small and highly efficient treatment systems at specific locations' in existing water supply networks. Such satellite water treatment systems would process relatively low flow 

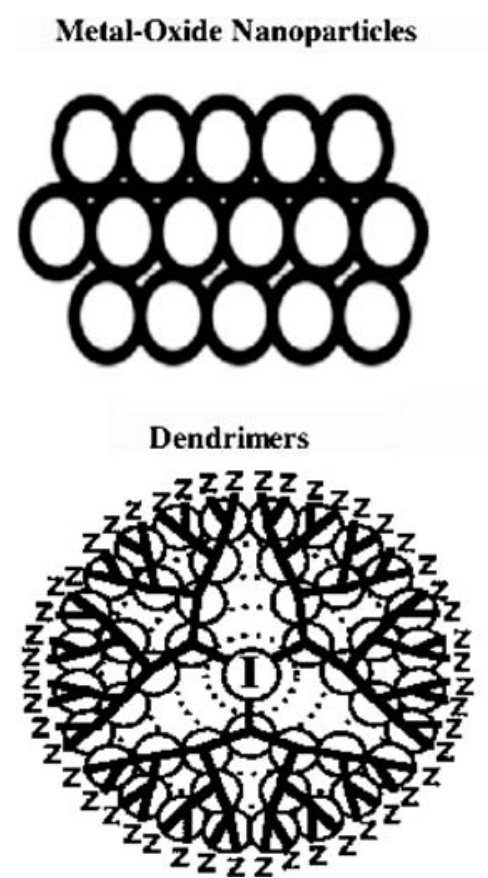

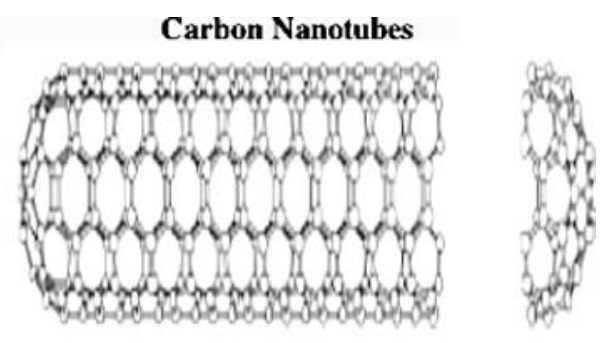

Zeolites

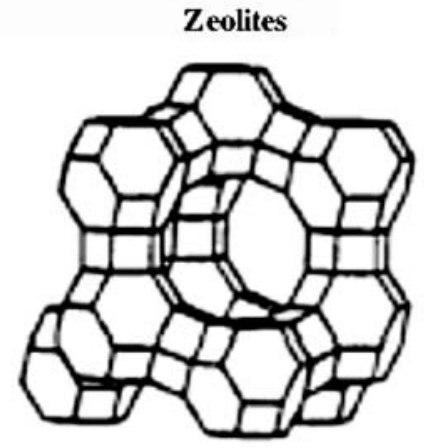

Figure 1. Selected nanomaterials currently being evaluated as functional materials for water purification.

rates and would use 'off-the-shelf treatment technologies of the most advanced nature (e.g., supraselective foul-resistant membrane separations, customized polymeric adsorbents and molecular sieves, supercritical water oxidation, etc.)' to meet the water needs of population clusters such as housing subdivisions, apartment complexes and commercial districts (Weber, 2002). The US Environmental Protection Agency (EPA) is also evaluating the use of a number of decentralized water treatment concepts as 'small system compliance technology' (USEPA, 1998). These include package treatment plants (i.e., factory assembled compact and ready to use water treatment systems), point-of-entry (POE) and point-of-use (POU) treatment units designed to process small amounts of water entering a given unit (e.g., building, office, household, etc.) or a specific tap/ faucet within the unit. The protection of water treatment systems against potential chemical and biological terrorist acts is also becoming a critical issue in water resources planning (USEPA, 2004).

Advances in nanoscale science and engineering are providing unprecedented opportunities to develop more cost effective and environmentally acceptable water purification processes. This article gives a brief overview of the use of nanomaterials in the purification of water contaminated by toxic metal ions, radionuclides, organic and inorganic solutes, bacteria and viruses. Because a comprehensive discussion of the applications of nanotechnology to water purification is beyond the scope of this overview, our main objectives here are to discuss the opportunities and challenges of using nanomaterials in the purification of surface water, groundwater and industrial wastewater streams. Figure 1 highlights four classes of nanoscale materials that are being evaluated as functional materials for water purification: (1) metal-containing nanoparticles, (2) carbonaceous nanomaterials, (3) zeolites and (4) dendrimers. These have a broad range of physicochemical properties that make them particular attractive as separation and reactive media for water purification. This article is divided into four sections. Following the introductory section, Section 2 'Nanomaterials and water purification: opportunities for improving and protecting water supplies' highlights recent advances in the development of novel water-purification functional materials (e.g., nanosorbents, redox and catalytically active nanoparticles, nanostructured membranes and 
bioactive active nanoparticles) and processes (e.g., dendrimer enhanced ultrafiltration). Section 3 'Nanomaterials and water purification: challenges' discusses some of the challenges associated with the use of nanomaterials in water purification. Section 4 'Summary and Outlook' provides a summary and outlook.

\section{Nanomaterials and water purification: opportunities for improving and protecting water supplies}

Recent advances suggest that many of the issues involving water quality could be resolved or greatly ameliorated using nanoparticles, nanofiltration or other products resulting from the development of nanotechnology. Innovations in the development of novel technologies to desalinate water are among the most exciting and promising. Utilization of specific nanoparticles either embedded in membranes or on other structural media that can effectively, inexpensively and rapidly render unusable water potable is being explored at a variety of institutions. In addition to obvious advantages for industrialized nations, the benefits for developing countries would also be enormous. Innovative use of nanoparticles for treatment of industrial wastewater is another potentially useful application. Many factories generate large amounts of wastewater. Removal of contaminants and recycling of the purified water would provide significant reductions in cost, time, and labor to industry and result in improved environmental stewardship. Aquifer and groundwater remediation are also critical issues, becoming more important as water supplies steadily decrease and demand continues to increase. Most of the remediation technologies available today, while effective, very often are costly and timeconsuming, particularly pump-and-treat methods. The ability to remove toxic compounds from subsurface and other environments that are very difficult to access in situ, and doing so rapidly, efficiently and within reasonable costs is the ultimate goal. Below, we highlight the results of selected studies on the use of nanomaterials as separation and reactive media for water purification.

\section{Nanosorbents}

Sorbents are widely used as separation media in water purification to remove inorganic and organic pollutants from contaminated water. Nanoparticles have two key properties that make them particularly attractive as sorbents. On a mass basis, they have much larger surface areas than bulk particles. Nanoparticles can also be functionalized with various chemical groups to increase their affinity towards target compounds. Several research groups are exploiting the unique properties of nanoparticles to develop high capacity and selective sorbents for metal ions and anions. Li et al. (2003) have investigated the sorption of $\mathrm{Pb}(\mathrm{II}), \mathrm{Cu}(\mathrm{II})$ and $\mathrm{Cd}(\mathrm{II})$ onto multiwalled carbon nanotubes (MWCNTs). They reported maximum sorption capacities of $97.08 \mathrm{mg} / \mathrm{g}$ for $\mathrm{Pb}(\mathrm{II})$, $24.49 \mathrm{mg} / \mathrm{g}$ for $\mathrm{Cu}(\mathrm{II})$ and $10.86 \mathrm{mg} / \mathrm{g}$ for $\mathrm{Cd}(\mathrm{II})$ at room temperature, $\mathrm{pH} 5.0$ and metal ion equilibrium concentration of $10 \mathrm{mg} / \mathrm{l}$. Li et al. (2003) also found that the metal-ion sorption capacities of the MWCNTs were 3-4 times larger than those of powder activated carbon and granular activated carbon, two commonly used sorbents in water purification. Qi \& Su (2004) have evaluated the sorption of $\mathrm{Pb}(\mathrm{II})$ onto chitosan nanoparticles $(40-100 \mathrm{~nm})$ prepared by ionic gelation of chitosan and tripolyphosphate. The phosphate-functionalized chitosan nanoparticles have a maximum $\mathrm{Pb}$ (II) sorption capacity of $398 \mathrm{mg} / \mathrm{g}$. Peng et al. (2005) have recently developed a novel sorbent with high surface area $\left(189 \mathrm{~m}^{2} / \mathrm{g}\right)$ consisting of cerium oxide supported on carbon nanotubes $\left(\mathrm{CeO}_{2}-\mathrm{CNT}\right)$. They showed that the $\mathrm{CeO}_{2}-\mathrm{CNT}$ particles are effective sorbents for $\mathrm{As}(\mathrm{V})$. Interestingly, Peng et al. (2005) found that the addition (from 0 to $10 \mathrm{mg} / \mathrm{l}$ ) of two divalent cations [Ca(II) and $\mathrm{Mg}(\mathrm{II})]$ resulted in a substantial increase of the amount of sorbed $\mathrm{As}(\mathrm{V})$ (from 10 to $82 \mathrm{mg} / \mathrm{g}$ ). Deliyanni et al. (2003) have also synthesized and characterized a novel $\mathrm{As}(\mathrm{V})$ sorbent consisting of akaganeite $[\beta-\mathrm{FeO}(\mathrm{OH})]$ nanocrystals. In addition, Lazaridis et al. (2005) have shown that nanocrystalline akaganeite is also an effective sorbent for $\mathrm{Cr}(\mathrm{VI})$.

Zeolites are effective sorbents and ion-exchange media for metal ions. NaP1 zeolites $\left(\mathrm{Na}_{6} \mathrm{Al}_{6}\right.$ $\left.\mathrm{Si}_{10} \mathrm{O}_{32}, 12 \mathrm{H}_{2} \mathrm{O}\right)$ have a high density of $\mathrm{Na}$ ion exchange sites. They can be inexpensively synthesized by hydrothermal activation of fly ash with low $\mathrm{Si} / \mathrm{Al}$ ratio at $150^{\circ} \mathrm{C}$ in $1.0-2.0 \mathrm{M} \mathrm{NaOH}$ solutions (Moreno et al., 2001). NaP1 zeolites have been evaluated as ion exchange media for the removal of heavy metals from acid mine 
wastewaters (Moreno et al., 2001). Alvarez-Ayuso et al. (2003) reported the successful use of synthetic $\mathrm{NaP} 1$ zeolites to remove $\mathrm{Cr}(\mathrm{III}), \mathrm{Ni}(\mathrm{II})$, $\mathrm{Zn}(\mathrm{II}), \mathrm{Cu}(\mathrm{II})$ and $\mathrm{Cd}(\mathrm{II})$ from metal electroplating wastewaters. Self-assembled monolayers on mesoporous supports (SAMMS) are providing novel opportunities to develop more effective sorbents for toxic metal ions (Yantasee et al., 2003), anions (Kelly et al., 2001) and radionuclides (Fryxell et al., 2005; Lin et al., 2005). These sorbents are made via surfactant templated synthesis of mesoporous ceramics. This produces nanoporous ceramic oxides with very large surface areas $\left(\sim 1000 \mathrm{~m}^{2} / \mathrm{g}\right)$ and high density of sorption sites that can be functionalized to increase their selectivity toward target pollutants.

Carbonaceous nanomaterials can serve as high capacity and selective sorbents for organic solutes in aqueous solutions. Mangun et al. (2001) have synthesized nanoporous activated carbon fibers (ACFs) with an average pore-size of $1.16 \mathrm{~nm}$ and surface areas ranging from 171 to $483 \mathrm{~m}^{2} / \mathrm{g}$. They measured the sorption of benzene, toluene, $p$ xylene and ethylbenzene onto the ACFs at $20^{\circ} \mathrm{C}$. Mangun et al. (2001) found that the sorption isotherms are adequately described by a Freundlich equation. In all cases, the ACFs had much higher organic sorption equilibrium constants than granular activated carbon. Peng et al. (2003) have evaluated the sorption of 1,2-dichlorobenzene (DCB) onto CNTs. They found that it takes only 40 min for DCB sorption onto the CNTs to reach equilibrium with a maximum sorption capacity of $30.8 \mathrm{mg} / \mathrm{g}$. Li et al. (2004) reported that MWCNTs were better sorbents of volatile organic compounds than carbon black in aqueous solutions. Fugetsu et al. (2004) have successfully encapsulated MWCNTs inside cross-linked alginate vesicles. The caged MWCNTs showed high sorption capacity and selectivity for four watersoluble dyes (acridine orange, ethidium bromide, eosin bluish and orange G). Zhao \& Nagy (2004) have synthesized hybrid inorganic-organic nanosorbents by incorporation of sodium dodecyl sulfate (SDS) into magnesium-aluminum layered double hydroxides (LDHs). They reported that the SDS functionalized $\mathrm{Mg} / \mathrm{Al} \mathrm{LDHs}$ had higher sorption capacity for chlorinated alkenes [tetrachloroethylene (PCE) and trichloroethylene (TCE)] in aqueous solutions than organoclays. Fullerenes can also serve as sorbents for polycyclic aromatic compounds (PAHs) such as naphthalene (Cheng et al., 2004). Finally, we would like to point out the recent synthesis and characterization of amphiphilic polyurethane nanoparticles that can sorb PAHs (e.g., naphthalene) and increase their bioavailability in aqueous solutions (Tungittiplakorn et al., 2004, 2005).

\section{Nanocatalysts and redox active nanoparticles}

Nanoparticles have great potential as water-purification catalysts and redox active media due their large surface areas and their size and shapedependent optical, electronic and catalytic properties (Obare \& Meyer, 2004). During the last decade, titanium dioxide $\left(\mathrm{TiO}_{2}\right)$ nanoparticles have emerged as promising photocatalysts for water purification (Adesina, 2004). $\mathrm{TiO}_{2}$ nanoparticles are very versatile; they can serve both as oxidative and reductive catalysts for organic and inorganic pollutants. The removal of total organic carbon from waters contaminated with organic wastes was greatly enhanced by the addition of $\mathrm{TiO}_{2}$ nanoparticles in the presence of ultraviolet light as shown by Chitose et al., (2003). Kabra et al. (2004) have recently reviewed the utilization of photocatalysts in the treatment of water contaminated by organic and inorganic pollutants. They documented the successful use of $\mathrm{TiO}_{2}$ nanoparticles to (i) degrade organic compounds (e.g. chlorinated alkanes and benzenes, dioxins, furans, PCBs, etc.) and (ii) reduce toxic metal ions [e.g., $\mathrm{Cr}(\mathrm{VI}), \operatorname{Ag}(\mathrm{I})$ and $\mathrm{Pt}(\mathrm{II})$ ] in aqueous solutions under UV light. The synthesis of visible light-activated $\mathrm{TiO}_{2}$ nanoparticles has attracted considerable interest (Asahi et al., 2001; Bae \& Choi, 2003; Adesina, 2004; Obare \& Meyer, 2004). One of the most cited studies in the field is that published by Ashasi et al. (2001). They synthesized $\mathrm{N}$-doped $\mathrm{TiO}_{2}$ nanoparticles that were capable of photodegrading methylene blue under visible light. Bae \& Choi (2003) have synthesized visible light-activated $\mathrm{TiO}_{2}$ nanoparticles based on $\mathrm{TiO}_{2}$ modified by ruthenium-complex sensitizers and $\mathrm{Pt}$ deposits. The $\mathrm{Pt} / \mathrm{TiO}_{2} / \mathrm{Ru}^{\mathrm{II}} \mathrm{L}_{3}$ nanoparticles drastically enhanced the rate of reductive dehalogenation of trichloroacetate and carbon tetrachloride in aqueous solutions under visible light.

Nanoscale zero valent iron $\left(\mathrm{Fe}^{0}\right)$ and bimetallic $\mathrm{Fe}^{0}$ particles have emerged as effective redox 
media for the detoxification of organic and inorganic pollutants in aqueous solutions. These nanomaterials $(10-100 \mathrm{~nm})$ have larger surface areas and reactivity than bulk $\mathrm{Fe}^{0}$ particles (Schrick et al., 2002; Zhang, 2003; Nurmi et al., 2005). Zhang (2003) has given an overview of the synthesis, characterization and use of nanoscale $\mathrm{Fe}^{0}$ particle and $\mathrm{Fe}^{0} / \mathrm{Pd}^{0}, \mathrm{Fe}^{0} / \mathrm{Pt}^{0}, \mathrm{Fe}^{0} / \mathrm{Ag}^{0}, \mathrm{Fe}^{0} /$ $\mathrm{Ni}^{0}$ and $\mathrm{Fe}^{0} / \mathrm{Co}^{0}$ in environmental remediation. These nanoparticles can reduce a variety of organic pollutants (e.g., chlorinated alkanes and alkenes, chlorinated benzenes, pesticides, organic dyes, nitro aromatics, PCBs) and inorganic anions (e.g., nitrates) in aqueous solutions to less toxic and recalcitrant by-products. $\mathrm{Fe}^{0}$ and bimetallic $\mathrm{Fe}^{0}$ nanoparticles have also been successfully used to reduce redox active metal ions such as $\mathrm{Cr}(\mathrm{VI})$ to less toxic and mobile $\mathrm{Cr}(\mathrm{III})$ species (Zhang, 2003). The immobilization of metalloporphyrinogens in soil-gel matrices has also been successfully used to prepare redox and catalytically active nanoparticles for the reductive dehalogenation of chlorinated organic compounds (PCE, TCE and carbon tetrachloride) in aqueous solutions (Dror et al., 2005).

\section{Nanostructured and reactive membranes}

Membrane processes such ultrafiltration as (UF), nanofiltration (NF) and reverse osmosis (RO) are emerging as key components of advanced water purification and desalination technologies (US Bureau of Reclamation, 2003). Van der Bruggen \& Vandercasteele (2003) have reviewed the use of nanofiltration to remove cations, natural organic matter, biological contaminants, organic pollutants, nitrates and arsenic from groundwater and surface water. Favre-Reguillon et al. (2003) showed that nanofiltration can be used to remove minute quantities of U(VI) from seawater. Mohsen et al. (2003) have evaluated the use of nanofiltration to desalinate water. They found that nanofiltration in combination with reverse osmosis could effectively render brackish water potable. Peltier et al. (2003) demonstrated an improvement in water quality for a large water distribution system using nanofiltration. Substantial reductions in the quantities of both organic and biological contaminants (e.g., bacteria and viruses) were achieved using this process.
Nanomaterials are providing novel opportunities to develop more efficient and cost effective nanostructured and reactive membranes for water purification and desalination. Srivastava et al. (2004) recently reported the successful fabrication of carbon nanotube filters. These new filtration membranes consist of hollow cylinders with radially aligned carbon nanotube walls. Srivastava et al. (2004) showed that the filters were effective at removing bacteria (Escherichia coli and Staphylococus aureus) and Poliovirus sabin 1 from contaminated water. The carbon nanotube filters are readily cleaned by ultrasonication and autoclaving. DeFriend et al. (2003 reported the successful fabrication of alumina UF membranes using alumina (A-alumoxanes) nanoparticles $(7-25 \mathrm{~nm})$. The pore-size, and molecular weight cut-off (MWCO) of the membranes depend to a large extent on the "uniformity' of the alumina nanoparticles. The new UF membranes, which have MWCO between 1000$10,000 \mathrm{Da}$ and average pore diameter of $4 \mathrm{~nm}$, showed selectivity toward a number of synthetic dyes (e.g., Direct Red 81, Direct Blue 71 and Direct Yellow 71). DeFriend et al. (2003) also showed that the selectivity and permeate flux through the UF membranes can be increased by doping the alumina nanoparticles with $\mathrm{Fe}, \mathrm{Mn}$ and La. Stanton et al. (2003) have fabricated novel NF membranes by deposition of 4.5-5.0 layer pairs of poly(styrene sulfonate)/poly(allylamine hydrochloride) onto porous alumina. The new NF membranes exhibit high water flux, high retention of divalent cations [Ca(II) and $\mathrm{Mg}$ (II)] and $\mathrm{Cl}^{-} / \mathrm{SO}_{4}{ }^{2-}$ selectivity ratios up to 80 . Note that Hollman \& Bhattacharaya (2004) have also prepared novel membranes with enhanced metal ion retention and permeate flux by deposition of multilayers of charged polypeptides [poly $(9 \mathrm{~L}-$ glutamic acid) or poly(L-lysine)] inside the pores of functionalized polycarbonate track-etched membranes (thickness $=10 \mu \mathrm{m}$ and pore diameter $=200 \mathrm{~nm}$ ). Finally, we would like to highlight the successful preparation of reactive membranes by incorporation of bimetallic $\mathrm{Fe}^{0}$ / $\mathrm{Pt}^{0}$ nanoparticles into cellulose acetate films by Meyer et al. (2004). The embedded metal domains of the membranes have an average diameter of $24 \mathrm{~nm}$ and were found to be very effective at reducing TCE with ethane as the only observed by-product. 


\section{Bioactive nanoparticles}

A variety of strong oxidants (e.g., chlorine) are used as disinfectants for pathogens (e.g., bacteria and viruses) in water treatment. Because these compounds tend to generate toxic disinfection byproducts such as trihalomethanes, haloacetic acids and aldehydes, alternative disinfectants are critically needed to comply with the Stage 1 Disinfection Byproduct Rule of the 1996 Safe Drinking Water Act Amendments (USEPA, 1998b). The mechanisms by which disinfectants such as chlorine inactivate waterborne pathogens include (1) impairment of pathogen cellular function by destruction of major constituents (e.g., cell wall), (2) interference with the pathogen cellular metabolic processes, and (3) inhibition of pathogen growth by blockage of the synthesis of key cellular constituents (e.g., DNA, coenzymes and cell wall proteins) (USEPA, 1999). Nanomaterials are also providing unprecedented opportunities to develop chlorine-free biocides. Stoimenov et al. (2002) showed that MgO nanoparticles are very effective biocides against Grampositive and Gram-negative bacteria (Escherichia coli and Bacillus megaterium) and bacterial spores (Bacillus subtillus). Characterization of the interactions of the nanoparticles with the bacteria by atomic force microscopy (AFM), transmission electron microscopy (TEM), and laser confocal microscopy showed considerable changes in the integrity of the cell membranes, resulting in the death of the bacteria in most cases (2002). Because $\operatorname{Ag}(\mathrm{I})$ and silver compounds have been used as antimicrobial compounds in various biomedical products and applications, several investigators have begun evaluating the use of silver nanoparticles as biocides. Sondi \& SalopekSondi (2004) have prepared stable Ag nanoparticles of narrow size distribution by reducing silver nitrate solutions with ascorbic acid in the presence of Daxad 19 (sodium salt of a highmolecular-weight naphthalene sulfonate formaldehyde condensate) as stabilizing agent. They found that Ag nanoparticles were effective biocides against Escherichia coli. Son et al. (2004) reported that cellulose acetate (CA) fibers with embedded Ag nanoparticles [prepared by direct electrospinning of a CA solution with silver nitrate followed by photoreduction] were also effective biocides against Gram-positive and
Gram-negative bacteria including Staphylococcus aureus, Escherichia coli, Klebsiella pneumoniae and Pseudomonas aeruginosa.

\section{Dendrimer enhanced ultrafiltration}

RO membranes have pore sizes of 0.1-1.0 nm and thus are very effective at retaining dissolved inorganic and organic solutes with molar mass below $1000 \mathrm{Da}$ (Zeman \& Zydney, 1996). NF membranes, on the other hand, are very effective at removing hardness (e.g., multivalent cations) and organic solutes with molar mass between 1000 3000 Da (e.g., natural organic material) (Zeman \& Zydney, 1996). However, high pressures are required to operate both RO and NF membranes. Conversely, UF membranes require lower pressure $(200-700 \mathrm{kPa})$. Unfortunately, they are not very effective at removing dissolved organic and inorganic solute with molar mass below 3000 Da. Advances in macromolecular chemistry such as the invention of dendritic polymers are providing unprecedented opportunities to develop effective UF processes for purification of water contaminated by toxic metal ions, radionuclides, organic and inorganic solutes, bacteria and viruses. Dendritic polymers, which include random hyperbranched polymers, dendrigraft polymers, dendrons and dendrimers, are relatively monodispersed and highly branched macromolecules with controlled composition and architecture consisting of three components: a core, interior branch cells and terminal branch cell (Fréchet \& Tomalia, 2001). Dendritic polymers exhibit many features that make them particularly attractive as functional materials for water purification. These 'soft' nanoparticles, with sizes in the range of $1-20 \mathrm{~nm}$, can be used as high capacity and recyclable watersoluble ligands for toxic metal ions, radionuclides and inorganic anions (Ottaviani et al., 2000; Birnbaum et al., 2003; Diallo et al., 2004). Dendritic polymers can also be used as (i) recyclable unimolecular micelles for recovering organic solutes from water (Arkas et al., 2003) and (ii) scaffolds and templates for the preparation of redox and catalytically active nanoparticles (Crooks et al., 2005). Dendritic polymers have also been successfully used as delivery vehicles or scaffolds for antimicrobial agents such as $\operatorname{Ag}(\mathrm{I})$ and quaternary ammonium chlorides (Balogh et al., 2001; Chen \& Cooper, 2002). 
One of the authors of this article (Diallo) has developed a dendrimer-enhanced ultrafiltration (DEUF) process (Figure 2) for recovering metal ions from aqueous solutions (Diallo, 2004; Diallo et al., 2005). As a proof-of-concept study, Diallo et al. (2005) tested the feasibility of using DEUF and poly(amidoamine) (PAMAM) dendrimers with ethylene diamine (EDA) core and terminal $\mathrm{NH}_{2}$ groups to recover $\mathrm{Cu}(\mathrm{II})$ ions from aqueous solutions. On a mass basis, the $\mathrm{Cu}(\mathrm{II})$ binding capacities of the PAMAM dendrimers are much larger and more sensitive to solution $\mathrm{pH}$ than those of linear polymers with amine groups. Separation of the dendrimer-Cu(II) complexes from solutions can be achieved simply by UF membranes with the appropriate MWCO. The metal ion laden dendrimers can be regenerated by decreasing the solution $\mathrm{pH}$ to 4.0 (Diallo et al., 2005); thus enabling the recovery of the bound $\mathrm{Cu}(\mathrm{II})$ ions and recycling of the dendritic polymer. PAMAM dendrimers have a very low tendency to foul commercially available regenerated cellulose (RC) membranes (Diallo et al., 2005). They also have much smaller intrinsic viscosities than linear polymers with the same molar mass because of their globular shape (Fréchet \& Tomalia, 2001). Thus, comparatively smaller operating pressure and energy consumption could be achieved with dendritic polymers in tangential/cross-flow UF systems typically used in water purification. Other applications of DEUF to water purification are discussed by Diallo (2004).

\section{Nanomaterials and water purification: challenges}

Nanomaterials are the drivers of the nanotechnology revolution. Thus, a key bottleneck to the applications of nanotechnology to water purification will be the availability of suppliers that can provide large quantities of nanomaterials at economically viable prices. The Freedonia group has recently completed a study of the nanomaterials industry (Freedonia, 2005). The study provides data on the demand of nanomaterials in the US for the years 2000 and 2003. It also includes forecasts of demand to the years 2008, 2013 and 2020 by classes of materials (e.g., metal oxides, clays, metals, polymers and chemicals, nanotubes, dendrimers, etc.) and by applications (e.g., abrasives; coatings, thin films, sunscreens; biocides; pharmaceuticals fillers and reinforcements; catalysts; structural materials, etc.). These forecasts anticipate that most nanomaterials will be nanoscale versions of established products such as silica, titanium dioxide, clays, metal powders,
Dendrimers

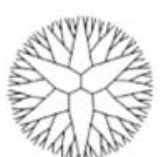

Core-Shell Tecto(dendrimers)

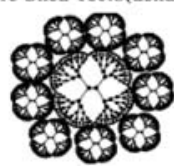

Dendrigraft Polymers

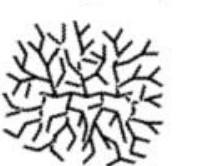

Hyperbranched Polymers

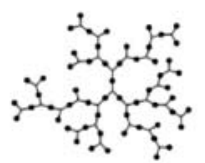

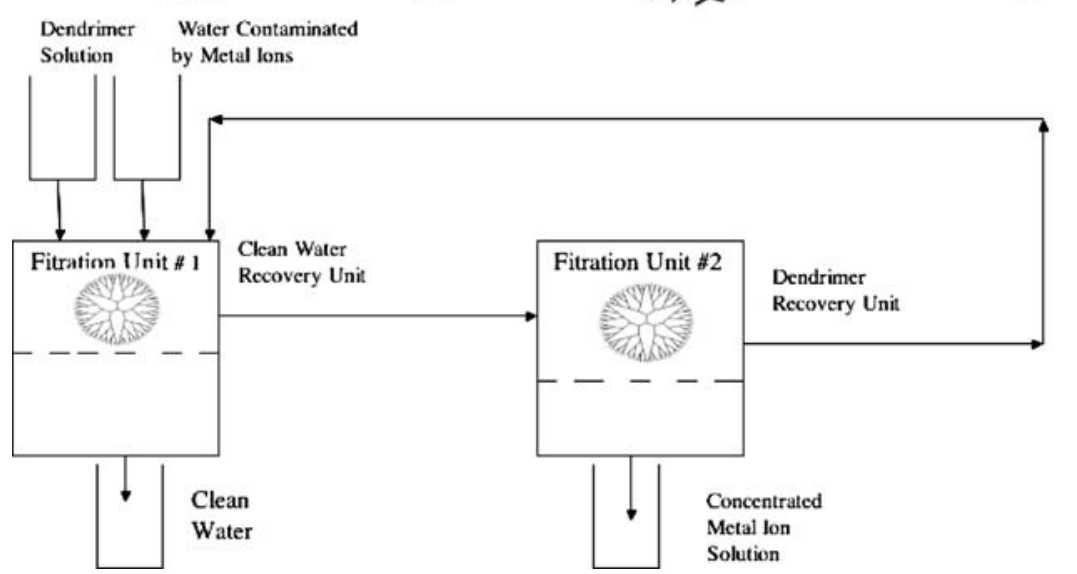

Figure 2. Recovery of metal ions from aqueous solutions by dendrimer enhanced filtration. Reprinted with permission from Environmental Science and Technology, 2005, 39: 1366-1377. Copyright 2005 American Chemical Society. 
polymers and chemicals in the next decade (Freedonia, 2005). Larger quantities of carbon nanotubes, fullerenes and dendrimers will also be available as these nanomaterials become key components of electronic products, drug delivery systems, batteries, fuel cells, etc. (Freedonia, 2005).

The integration of nanomaterials into existing water purification systems is another key challenge. Membrane processes such as RO, NF and UF are becoming the 'standard' water purification technologies for public utilities and industry because they are flexible, scalable, modular and relatively easy to operate and maintain. The DEUF process shown in Figure 2 combines dendritic nanoscale chelating agents with commercially available UF membranes. Thus, it can be readily integrated into existing water purification systems or processes once a suitable and cost effective dendritic chelating has been selected or synthesized. However, more laboratory investigations and pilot scale testing will be needed to integrate novel nanostructured and reactive membranes into existing water purification systems. The scale-up of $\mathrm{TiO}_{2}$-based photocatalytic reactors is also poorly understood (Adesina, 2004) even though significant progress is being made toward the development of visible light-activated $\mathrm{TiO}_{2}$ nanoparticles (Asahi et al., 2001; Bae \& Chae, 2003; Obare \& Meyer, 2004). Conversely, we believe that nanosorbents (e.g., inorganic nanocrystals, carbonaceous nanoparticles and zeolites), redox active nanoparticles (e.g., $\mathrm{Fe}^{0}$ and bimetallic $\mathrm{Fe}^{0}$ ) and bioactive nanoparticles (e.g., $\mathrm{MgO}$ and $\mathrm{Ag}$ ) can be readily integrated into existing water treatment plants. Here a major challenge will be to develop cost effective and environmentally acceptable separation and reactive media that can be deployed in composite packed-bed reactors (Figure 3) for purification of water contaminated by mixtures of (i) metal ions, (ii) organic solutes and (iii) bacteria.

The environmental fate and toxicity of a material are critical issues in materials selection and design for water purification. Not much is known about the environmental fate, transport and toxicity of nanomaterials (Colvin, 2003; Lecoanet et al., 2004a,b). No systematic investigations of the hydrolytic, oxidative, photochemical and biological stability of nanomaterials (e.g., dendrimers, carbonaceous nanoparticles, metal oxides, et) in natural and engineered environmental systems

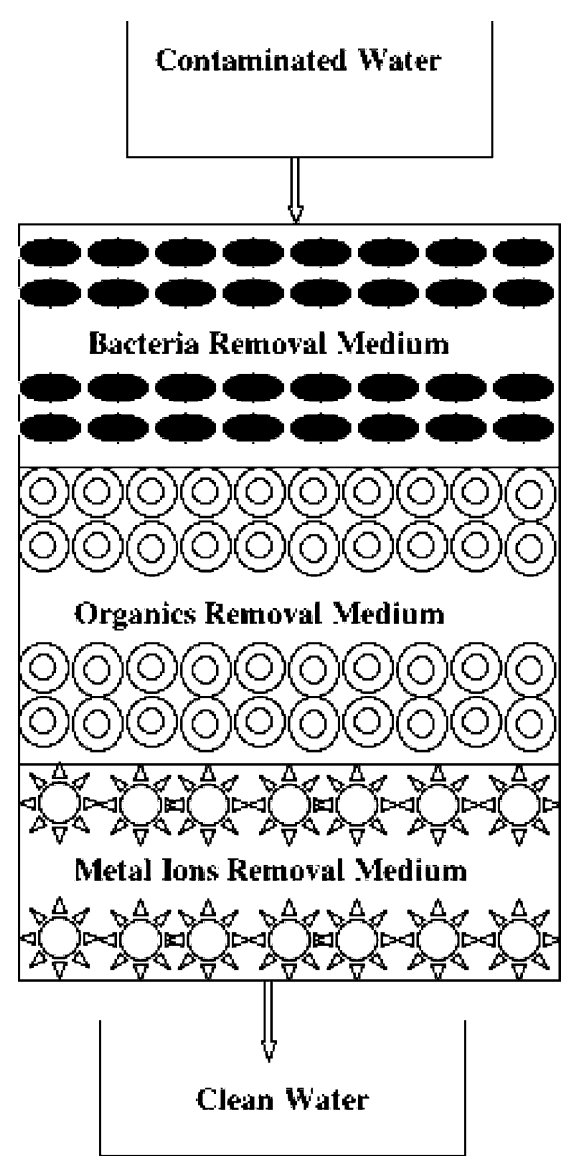

Figure 3. Schematic of a composite nanomaterial packedbed reactor for purification of water contaminated by mixtures of (i) metal ions, (ii) organic solutes and (iii) bacteria.

have been published in the peer-reviewed literature to the best of our knowledge. A number of in vitro and in vivo measurements of toxicity and biodistribution have been carried out (Malik et al., 2000; Jevprasesphant et al., 2003; Hong et al., 2004) in support of the use of dendrimers as DNA transfection reagents, metal ion contrast agent carriers for magnetic resonance imaging, targeted drug and therapeutic agent delivery vehicles and viral inhibitors (Fréchet \& Tomalia, 2001). These overall studies suggest that non-toxic and biodegradable dendrimers can be synthesized through a judicious selection of the dendrimer building blocks (e.g., core and terminal group). The design and synthesis of biocompatible carbon nanotubes (CNTs) and fullerenes are, on the other hand, much more challenging. Only a few peer-reviewed 
studies of the toxicity of CNTs and fullerenes have been published (Lam et al., 2004; Oberdöster, 2004; Jia et al., 2005). These studies showed that underivatized CNTs and fullerenes tend to be water insoluble and toxic. However, CNTs and fullerenes can be functionalized with various functional groups (e.g. hydroxyl, carboxyl, amines, etc.) to increase their water solubility and biocompatibility in some cases (Sayes et al., 2004; Bianco et al., 2005). Finally, we would to point out that metal-containing particles also exhibit a sizedependent toxicity (Chen, 2004). Thus, a key challenge will be to gain regulatory and public acceptance for using nanomaterials in water purification because of their unknown toxicity and environmental impact.

\section{Summary and outlook}

Clean water is essential to human health and is a critical feedstock in a variety of key industries including electronics, pharmaceuticals and food. The world is facing formidable challenges in meeting rising demands of clean water as the available supplies of freshwater are decreasing due to (i) extended droughts, (ii) population growth, (iii) more stringent health-based regulations, and (iv) competing demands from a variety of users. Nanomaterials have a number of key physicochemical properties that make them particularly attractive as separation media for water purification. On a mass basis, they have much large surface areas than bulk particles. Nanomaterials can also be functionalized with various chemical groups to increase their affinity toward a given compound. They can also serve as high capacity/ selectivity and recyclable ligands for toxic metal ions, radionuclides, organic and inorganic solutes/ anions in aqueous solutions. Nanomaterials also provide unprecedented opportunities to develop more efficient water-purification catalysts and redox active media due their large surface areas and their size and shape-dependent optical, electronic and catalytic properties. Nanomaterials are also being used to develop chlorine-free biocides through functionalization with chemical groups that selectively target key biochemical constituents of waterborne bacteria and viruses.

We envision that nanomaterials will become critical components of industrial and public water purification systems as more progress is made toward the synthesis of cost-effective and environmentally acceptable functional materials. The development of smart membranes with biofilmresistant surfaces and embedded sensors/actuators that can automatically adjust membrane performance and selectivity by the year 2020 is a key long-term goal of the Desalination and Water Purification Roadmap prepared by the US Bureau of Reclamation and Sandia National Laboratories (US Bureau of Reclamation, 2003). We anticipate that nanomaterials will be key components of such membranes. The development of visible light-activated $\mathrm{TiO}_{2}$ nanoparticles could have a significant impact on water supply. The controlled release of these nanoparticles into surface waters exposed to sunlight could significantly reduce organic carbon load through oxidative photochemical degradation. In the near-term, we also anticipate nanomaterials will help solve challenging water purification problems including: (1) the desalination of brackish water (US Bureau of Reclamation, 2003); (2) the recovery of valuable and toxic metal ions from membrane concentrates thereby facilitating brine disposal (Van der Bruggen et al. 2003); (3) the development of chlorine-free biocides (USEPA, 1999); and (4) the purification of water contaminated by toxic contaminants such as perchlorate, pharmaceuticals, chiral compounds and endocrine disrupting compounds (Richardson, 2003).

\section{Acknowledgements}

Nora Savage thanks Stephen Lingle and Estella Waldman of the U.S. Environmental Protection Agency for their efforts in editing this article. Mamadou Diallo thanks the National Science Foundation (NSF Grants CTS-0086727 and CTS0329436) and the US Environmental Protection Agency (NCER STAR Grant R829626) for funding his research on the use of dendritic polymers as functional materials for water purification. Partial funding for this research was also provided by the Department of Energy (Cooperative Agreement EW15254), the W. M. Keck Foundation, the National Water Research Institute (Research Project Agreement NO 05-TT-004) and the NSF Sponsored Cornell University Nanobiotechnology Center. This center is funded by the STC Program of the National Science Foundation under Agreement No. ECS-9876771. 


\section{References}

Adesina A.A., 2004. Industrial exploitation of photocatalysis progress, perspectives and prospects. Catal. Surv. Asia 8(4), 265-273.

Aorkas M., D. Tsiourvas \& C.M. Paleos, 2003. Functional dendrimeric "nanosponges" for the removal of polycyclic aromatic hydrocarbons from water. Chem. Mater 15(14), 2844-2847.

Asahi R., T. Morikawa, T. Ohwaki, K. Aoki \& Y. Taga, 2001. Visible-light photocatalysis in nitrogen-doped titanium oxides. Science 293(5528), 269-271.

Alvarez-Ayuso E., A. Garcia-Sanchez \& X. Querol, 2003. Purification of metal electroplating waste waters using zeolites. Water Res. 37, 4855-4862.

Bae E. \& W. Choi, 2003. Highly enhanced photoreductive degradation of perchlorinated compounds on dye-sensitized metal/ $\mathrm{TiO} 2$ under visible light. Environ. Sci. Technol. 37(1), 147-152.

Balogh L., D.R. Swanson, D.A. Tomalia, G.L. Hagnauer \& A.T. McManus, 2001. Dendrimer-silver complexes and nanocomposites as antimicrobial agents. Nano Lett. 1(1), $18-21$.

Bianco A., K. Kostarelos, C.D. Partidos \& M. Prato, 2005. Biomedical applications of functionalized carbon nanotubes. Chem. Commun. 5, 571-577.

Birnbaum E.R., K.C. Rau \& N.N. Sauer, 2003. Selective anion binding from water using soluble polymers. Sep. Sci. Technol. 38(2), 389-404.

Chen C.Z.S. \& S. Cooper, 2002. Interactions between dendrimer biocides and bacterial membranes. Biomaterials 23(16), 3359-3368.

Chen J., M. Liu, L. Zhang, J. Zhang \& L. Jin, 2003. Application of nano $\mathrm{TiO}_{2}$ towards polluted water treatment combined with electro-photochemical method. Water Res. 37, 3815-3820 .

Chen M.D., 2004. Effects of nanophase materials $(<=20 \mathrm{~nm})$ on biological responses. J. Environ. Sci. Health A. 39(10), 2691-2705.

Cheng X., A.T. Kan \& M.B. Tomson, 2004. Naphthalene Adsorption and Desorption from Aqueous $\mathrm{C}_{60}$ Fullerene. J. Chem. Eng. Data. 49, 675-683.

Chitose N., S. Ueta \& T.A. Yamamoto, 2003. Radiolysis of aqueous phenol solutions with nanoparticles. 1. Phenol degradation and TOC removal in solutions containing $\mathrm{TiO}_{2}$ induced by UV, gamma-ray and electron beams. Chemosphere 50(8), 1007-1013.

DeFriend K.A., M.R. Wiesner \& A.R. Barron, 2003. Alumina and aluminate ultrafiltration membranes derived from alumina nanoparticles. J. Membr. Sci. 224(1-2), 11-28.

Colvin V.L., 2003. The potential environmental impact of engineered nanomaterials. Nature Biotechnol. 10, 1166-1170.

Deliyanni E.A., D.N. Bakoyannakis, A.I. Zouboulis \& K.A. Matis, 2003. Sorption of $\mathrm{As}(\mathrm{V})$ ions by akaganéite-type nanocrystals. Chemosphere 50(1), 155-163.

Diallo M.S., S. Christie, P. Swaminathan, J.H. Johnson Jr. \& W.A. Goddard III, 2005. Dendrimer enhanced ultrafiltration. 1. recovery of $\mathrm{Cu}(\mathrm{II})$ from aqueous solutions using $\mathrm{Gx}-\mathrm{NH}_{2}$
PAMAM dendrimers with ethylene diamine core. Environ. Sci. Technol. 39(5), 1366-1377.

Diallo M.S., S. Christie, P. Swaminathan, L. Balogh, X. Shi, W. Um, C. Papelis, W.A. Goddard III \& J.H. Johnson Jr., 2004. Dendritic chelating agents 1 . $\mathrm{Cu}(\mathrm{II})$ binding to ethylene diamine core poly(amidoamine) dendrimers in aqueous solutions. Langmuir 20, 2640-2651.

Diallo M.S., 2004. Water treatment by dendrimer enhanced filtration. US Patent Pending. Unpublished.

Dror I., D. Baram \& B. Berkowitz, 2005. Use of nanosized catalysts for transformation of chloro-organic pollutants. Environ. Sci. Technol. 39(5), 1283-1290.

Favre-Reguillon A., G. Lebuzit, J. Fooz \& A. Guy, 2003. Selective concentration of uranium from seawater by nanofiltration. Ind. Eng. Chem. Res. 42, 5900-5904.

Fréchet J.M.J. \& D.A. Tomalia, (Eds.). 2001. Dendrimers and Other Dendritic Polymers. New York: Wiley and Sons.

Freedonia Group, Inc., 2005. Nanomaterials - market size, market share, market leaders, demand forecast, sales, company profiles, market research, industry trends. Study \#: 1887. URL: http://www.freedoniagroup.com/Nanomaterials.html.

Fryxell G.E., Y. Lin, S. Fiskum, J.C. Birnbaum, H. Wu, K. Kemner \& S. Kelly, 2005. Self-assembled monolayers on mesoporous supports. Environ. Sci. Technol. 39(5), 1324-1331.

Fugetsu B., S. Satoh, T. Shiba, T. Mizutani, Y.B. Lin, N. Terui \&. Al. 2004. Caged multiwalled carbon nanotubes as the adsorbents for affinity-based elimination of ionic dyes. Environ. Sci. Technol. 38, 6890-6896.

Hollman A.M. \& D. Bhattacharyya, 2004. Pore assembled multilayers of charged polypeptides in microporous membranes for ion separation. Langmuir 20(13), 5418-5424.

Hong S.P., A.U. Bielinska, A. Mecke, B. Keszler, J.L. Beals, X.Y. Shi, L. Balogh, B.G. Orr, J.R. Baker \& M.M.B. Holl, 2004. Interaction of poly(amidoamine) dendrimers with supported lipid bilayers and cells: Hole formation and the relation to transport. Bioconjugate Chem. 15, 774-782.

Jia G., H. Wang, L. Yan, X. Wang, R. Pei, T. Yan, Y. Zhao \& X. Guo, 2005. Cytotoxicity of carbon nanomaterials: Singlewall nanotube, multi-wall nanotube, and fullerene. Environ. Sci. Technol. 39(5) 1378-1383.

Jevprasesphant R., J. Penny, D. Attwood, N.B. McKeown \& A. D'Emanuele, 2003. Engineering of dendrimer surfaces to enhance transepithelial transport and reduce cytotoxicity. Pharm. Res. 20(10), 1543-1550.

Kabra K., R. Chaudhary \& R.L. Sawhney, 2004. Treatment of hazardous organic and inorganic compounds through aqueous-phase photocatalysis: A review. Ind. Eng. Chem. Res. 43(24), 7683-7696.

Kelly S.D., K.M. Kemmer, G.E. Fryxell, J. Liu, S.V. Mattigod \& K.F. Ferris, 2001. X-ray-absorption fine-structure spectroscopy study of the interactions between contaminant tetrahedral anions and self-assembled monolayers on mesoporous supports. J. Phys. Chem. B. 105(27), 6337-6346.

Lam C., J.T. James, R. McCluskey \& R.L. Hunter, 2004. Pulmonary toxicity of carbon nanotubes in mice 7 and 90 days after intratracheal instillation. Toxicol. Sci. 77, $126-134$. 
Lazaridis N.K., D.N. Bakoyannakis \& E.A. Deliyanni, 2005. Chromium(VI) sorptive removal from aqueous solutions by nanocrystalline akaganeite. Chemosphere 58(1), 65-73.

Lecoanet H.F., J.Y. Bottero \& M.R. Wiesner, 2004. Laboratory assessment of the mobility of nanomaterials in porous media. Environ. Sci. Technol. 38(19), 5164-5169.

Lecoanet H.F. \& M.R. Wiesner, 2004. Velocity effects on fullerene and oxide nanoparticle deposition in porous media. Environ. Sci. Technol. 38(19), 5164-5169 .

Li Y.-H., J. Ding, Z.K. Luan, Z.C. Di, Y.F. Zhu, CL Xu, D.H. Wu \& B.Q. Wei, 2003. Competitive adsorption of $\mathrm{Pb}^{2}+$, $\mathrm{Cu}^{2+}$ and $\mathrm{Cd}^{2+}$ ions from aqueous solutions by multiwalled carbon nanotubes. Carbon 41(14), 2787-2792.

Li Q.L, D.X. Yuan \& Q.M. Lin, 2004. Evaluation of multiwalled carbon nanotubes as an adsorbent for trapping volatile organic compounds from environmental samples. J. Chromatogr. 1026, 283-288.

Lin Y., S.K. Fiskum, W. Yantasee, H. Wu, S.V. Mattigod, E. Vorpagel, G.E. Fryxell, K.N. Raymond \& J. Xu, 2005. Incorporation of hydroxypiridinone ligands into self-assembled monolayers on mesoporous supports for selective actinide sequestration. Environ. Sci. Technol. 39(5), 1332-1337.

Malik N., R. Wiwattanapatapee, R. Klopsch, K. Lorenz, H. Frey, J.W. Weener, E.W. Meijer, W. Paulus \& R. Duncan, 2000. Relationship between structure and biocompatibility in vitro, and preliminary studies on the biodistribution of I-125labelled polyamidoamine dendrimers in vivo. J. Control. Release 65((1-2), 133-148.

Mangun C.L., Z.R Yue, J. Economy, S. Maloney, P. Kemme \& D. Cropek, 2001. Adsorption of organic contaminants from water using tailored ACFs Carbon. Chem. Mater. 13, 23562360.

Meyer D.E., K. Wood, L.G. Bachas \& D. Bhattacharyya, 2004. Degradation of chlorinated organics by membrane-immobilized nanosized metals. Environ. Prog. 23(3), 232-242.

Mohsen M.S., J.O. Jaber \& M.D. Afonso, 2003. Desalination of brakish water by nanofiltration and reverse osmosis. Desalination 157(1), 167-167.

Moreno N., X. Querol \& C. Ayora, 2001. Utilization of zeolites synthesized from coal fly ash for the purification of acid mines water. Environ. Sci. Technol. 35, 3526-3534.

Nurmi J.T., P.G. Tratnyek, V. Sarathy, D.R. Baer, J.E. Amonette, K. Pecher, C. Wang, J.C. Lineham, D.W. Matson, R.L. Penn \& M.D. Driessen, 2005. Characterization and properties of metallic iron nanoparticles: spectroscopy, electrochemistry, and kinetics. Environ. Sci. Technol. 39(5), $1221-1230$.

Obare S.O. \& G.J. Meyer, 2004. Nanostructured materials for environmental remediation of organic contaminants in water. J. Environ. Sci. Health A. 39(10), 2549-2582.

Oberdörster E., 2004. Manufactured nanomaterials (Fullerenes, C-60) induce oxidative stress in the brain of juvenile largemouth bass. Environ. Health Pers. 112(10), 1058-1062.

Ottaviani M.F., P. Favuzza, M. Bigazzi, N.J. Turro, S. Jockusch \& D.A. Tomalia, 2000. A TEM and EPR investigation of the competitive binding of uranyl ions to starburst dendrimers and liposomes: Potential use of dendrimers as uranyl ion sponges. Langmuir 16(19), 7368-7372.
Peltier S., E. Cotte, D. Gatel, L. Herremans \& J. Cavard, 2003. Nanofiltration improvements of water quality in a large distribution system. Water Sci. Tech.: Water Supply 3, 193-200.

Peng X., Z. Luan, J. Ding, Z. Di, Y. Li \& B. Tian, 2005. Ceria nanoparticles supported nanotubes for the removal of arsenate from water. Mater. Lett. 59, 399-403.

Peng X.J., Y.H. Li, Z.K. Luan, Z.C. Di, H.Y. Wang, B.H. Tian \& Z.P. Jia, 2003. Adsorption of 1,2-dichlorobenzene from water to carbon nanotubes. Chem. Phys. Lett. 376(1-2), 154-158.

Qi L. \& Z. Xu, 2004. Lead sorption from aqueous solutions on chitosan nanoparticles. Colloid. Surf. A. 251(1-3), 183-190.

Richardson S., 2003. Water analysis emerging contaminants and current issues. Anal. Chem. 75(12), 2831-2857.

Sayes C.M., J.D. Fortner, W. Guo, D. Lyon, A.M. Boyd, K.D. Ausman, Y.J. Tao, B. Sitharaman, L.J. Wilson, J.B. Hughes, J.L. West \& V.L. Colvin, 2004. The differential cytotoxicity of water-soluble fullerenes. Nano Lett. 4(10), 1881-1887.

Schrick B., J.L. Blough, A.D. Jones \& T.E. Mallouk, 2002. Hydrodechlorination of trichloroethylene to hydrocarbons using bimetallic nickel-iron nanoparticles. Chem. Mater. 14(12), 5140-5147.

Scott R.W.J., O.M. Wilson \& R.M. Crooks, 2005. Synthesis, characterization, and applications of dendrimer-encapsulated nanoparticles. J. Phys. Chem. B. 109(2), 692-704 .

Son W.K., J.H. Youk, T.S. Lee \& W.H. Park, 2004. Preparation of antimicrobial ultrafine cellulose acetate fibers with silver nanoparticles. Macromol. Rapid Commun. 25(18), 1632-1637.

Sondi I. \& B. Salopek-Sondi, 2004. Silver nanoparticles as antimicrobial agent: A case study on E-coli as a model for Gram-negative bacteria. J. Coll. Interf. Sci. 275(1), 177-182.

Srivastava A., O.N. Srivastava, S. Talapatra, R. Vajtai \& P.M. Ajayan, 2004. Nature Mater. 3(9): 610-614.

Stanton B.W., J.J. Harris, M.D Miller \& M.L. Bruening, 2003. Ultrathin, multilayered polyelectrolyte films as nanofiltration membranes. Langmuir 19(17), 7038-7042.

Stoimenov P.K., R.L. Klinger, G.L. Marchin \& K.J. Klabunde, 2002. Metal oxide nanoparticles as bactericidal agents. Langmuir 18(17), 6679-6686.

Tungittiplakorn W., L.W. Lion, C. Cohen \& J.Y. Kim, 2004. Engineered polymeric nanoparticles for soil remediation. Environ. Sci. Technol. 38(5), 1605-1610.

Tungittiplakorn W., C. Cohen \& L.W. Lion, 2005. Engineered polymeric nanoparticles for bioremediation of hydrophobic contaminants. Environ. Sci. Technol. 39(5), 1354-1358.

Vander Bruggen B., L. Lejon \& C. Vandecasteele, 2003. Reuse, treatment, and discharge of the concentrate of pressuredriven membrane processes. Environ. Sci. Technol. 37(17), 3733-3738.

Vander Bruggen B. \& C. Vandecasteele, 2003. Removal of pollutants from surface water and groundwater by nanofiltration overview of possible applications in the drinking water industry. Environ. Pollut. 122, 435-445.

US Bureau of Reclamation and Sandia National Laboratories, 2003. Desalination and water purification technology roadmap - a report of the executive committee. Water Purification 
Research and Development Program Report No 95, US Department of Interior, Bureau of Reclamation, January 2003.

US Environmental Protection Agency, 1998a. Variance technology findings for contaminants regulated before 1996. EPA Office of Water Report 815-R-98-003.

US Environmental Protection Agency. 1998b. Microbial and disinfection by-product rules. Federal Register 63(241), 69389-69476.

US Environmental Protection Agency, 1999. Alternative disinfectants and oxidants guidance manual. EPA Office of Water Report 815-R-99-014.

US Environmental Protection Agency, 2004. Water security research and technical support action plan. EPA Office Research and Development and Office of Water Report EPA/600/R-04/063.
Weber W.J. Jr., 2002. Distributed optimal technology networks: A concept and strategy for potable water sustainability. Water Sci. Technol. 46(6-7), 241-246.

Yantasee W., Y. Lin, G.E. Fryxell, B.J. Busche \& J.C. Birnbaum, 2003. Removal of heavy metals from aqueous solution using novel nanoengineered sorbents: Self-assembled carbamoylphosphonic acids on mesoporous silica. Separ. Sci. Technol. 38(15), 3809-3825.

Zhang W.-X., 2003. Nanoscale iron particles for environmental remediation. J. Nanopart. Res. 5, 323-332.

Zeman L.J. \& A.L. Zydney, 1996. Microfiltration and Ultrafiltration. New York: Marcel Dekker principles and applications.

Zhao H.T. \& K.L. Nagy, 2004. Dodecyl sulfate-hydrotalcite nanocomposites for trapping chlorinated organic pollutants in water. J. Coll. Interf. Sci. 274(2), 613-624. 